University of Texas at El Paso

ScholarWorks@UTEP

$11-2020$

\title{
Being Active in Research Makes a Person a Better Teacher and Even Helps When Working for a Company
}

\author{
Francisco Zapata \\ The University of Texas at El Paso, fcozpt@outlook.com \\ Olga Kosheleva \\ The University of Texas at El Paso, olgak@utep.edu \\ Vladik Kreinovich \\ The University of Texas at El Paso, vladik@utep.edu
}

Follow this and additional works at: https://scholarworks.utep.edu/cs_techrep

Part of the Mathematics Commons

Comments:

Technical Report: UTEP-CS-20-118

Published in International Mathematical Forum, 2020, Vol. 15, No. 8, pp. 417-420.

\section{Recommended Citation}

Zapata, Francisco; Kosheleva, Olga; and Kreinovich, Vladik, "Being Active in Research Makes a Person a Better Teacher and Even Helps When Working for a Company" (2020). Departmental Technical Reports (CS). 1519.

https://scholarworks.utep.edu/cs_techrep/1519

This Article is brought to you for free and open access by the Computer Science at ScholarWorks@UTEP. It has been accepted for inclusion in Departmental Technical Reports (CS) by an authorized administrator of ScholarWorks@UTEP.For more information, please contact Iweber@utep.edu. 


\title{
Being Active in Research \\ Makes a Person a Better Teacher and Even Helps When Working for a Company
}

\author{
Francisco Zapata ${ }^{1}$, Olga Kosheleva ${ }^{2}$ and \\ Vladik Kreinovich ${ }^{3}$ \\ ${ }^{1}$ Department of Industrial, Manufacturing, \\ and Systems Engineering \\ ${ }^{2}$ Department of Teacher Education \\ ${ }^{3}$ Department of Computer Science \\ University of Texas at El Paso \\ $500 \mathrm{~W}$. University \\ El Paso, TX 79968, USA \\ fcozpt@outlook.com, olgak@utep.edu,vladik@utep.edu
}

\begin{abstract}
At first glance, it looks like being active in research is not necessarily related to a person's success in being a teacher or being a productive company employee - moreover, it looks like research distracts from other tasks. Somewhat surprisingly, however, in practice, the best teachers and the best employees are actually the ones who are active in research. In this paper, we provide an explanation for this seemingly counterintuitive phenomenon.
\end{abstract}

Mathematics Subject Classification: 90C90 91C99

Keywords: research, teaching, work, calculus, objective function

\section{Formulation of the Problem}

Research, teaching and work: common attitude. Many folks, including many politicians, feel that professors spend too much time on research. There seems to be no direct link between research activity and teaching - especially 
when we talk about teaching introductory classes. So, it seems that we could save money if - at least in teaching introductory classes - we replace research professors with instructors who do not do research at all and who can thus spend all their working time on teaching.

Similarly, many companies view most of their employees' research as a waste of company resources - to the extent that sometimes, people who want to get employed by these companies do not even mention their PhD degrees in their resumes.

But in practice, being active in research helps. Surprisingly, empirically, most active researchers are better teachers that instructors who are not active in research.

This phenomenon is surprising not only to lay folks, it is surprising to many people from the academia as well. For example, one of our Russian colleagues Andrei Finkelstein was asked to help with TV teaching of physics to high school students. You clearly do not need to be an active researcher in astrophysics (as our colleague was) to teach Newton's laws - but, surprisingly to him, his lectures were much more popular and much more successful than previously recorded lectures by experienced school teachers, teachers who were not active in physics research at all.

Similarly, when a $\mathrm{PhD}$ is hired by a company, when tasks are routine, he/she may not be appreciated - while others spend all their efforts on the company's tasks, this person inevitably thinks about research, and this slows down his/her productivity. But in real life, tasks are rarely always routine if this was the case, these tasks would have been automated long time ago. Eventually, non-routine, creative tasks appear - and here a person who is active in research, who has an experience and a habit of finding creative solutions to challenging problems, really shines - and more than compensates his/her previously non-stellar performance.

A word of caution. Of course, the relation between research activity and teaching is not absolute: there are active researchers who are lousy teachers and there excellent teachers who are active in research.

However, in general, active researchers seem to be better teachers.

How can we explain this phenomenon? A natural question is: how can we explain this empirical phenomenon - that being active in research, in general, helps teach better and makes a person a more effective company employee?

\section{Our Explanation}

Let us describe activity in research in precise terms. Activity or nonactivity in research refers to a person's position with respect to knowledge: 
- people who are active in research are - in their research area - on the cutting edge of knowledge, while

- people who are not active in research are not on the edge.

In other words, we can consider the set $S$ of all possible combinations of knowledge. We can then place each person, based on his/her knowledge, at one of the locations $s$ within this set.

In this arrangement, as we have just argued:

- people who are active in research are placed on the border $B$ of this set, while

- others are placed in the interior of this set.

What is our objective function? In both teaching and success for a company, we are looking for the best value of the corresponding objective function $f(s)$ :

- for teaching, this function describes teaching success;

- for a company, $f(s)$ is the success of achieving company's goals.

From this viewpoint, the question is: where on the set $S$ does this objective function attains its largest value?

Known facts from calculus. In general, the largest value of a function on a set $S$ is attained:

- either at an interior local maximum,

- or at one of points in the border;

see, e.g., $[1,2]$.

For any function $f(s)$, if the region $S$ is small enough, the probability that one of the local maxima is contained in this set is close to 0. So, for small sets, we can — with large degree of confidence — conclude that the maximum is attained at one of the border points.

Can we apply this mathematical fact to our problem? Is our set $S$ small? In the great scheme of things, taking into account how many things we still do not know (in spite of all the progress of science) - definitely yes, the set $S$ describing current knowledge is small. This set $S$ is increasing all the time, but, from the viewpoint of eternity, it is small.

The resulting explanation. Thus, to the set $S$, we can apply the above general conclusion: that the largest value of teaching efficiency, the largest value of employee efficiency are attained at the border of the set $S$, i.e., for people who are active in research. 


\section{Acknowledgments}

This work was supported in part by the National Science Foundation grants 1623190 (A Model of Change for Preparing a New Generation for Professional Practice in Computer Science), and HRD-1834620 and HRD-2034030 (CAHSI Includes).

\section{References}

[1] T. M. Apostol, Calculus, Wiley, New York, 1991.

[2] M. Spivak, Calculus, Publish or Perish Publ., 2008.

Received: November 24, 2020 